\title{
IMMUNOLOGICAL STUDIES ON AMMONIA CONTROL IN CULTURED SEABASS
}

\author{
KHALIL R.H. ; AMANY M. DIAB ${ }^{* *}$ and EL-GOHARY M.S ** \\ *Department of poultry and fish diseases Faculty of Veterinary Medicine Alexandria University. \\ ** Department of fish diseases Animal Health Research Institute Kafr El-Sheikh branch.
}

Email: fishyyanew@yahoo.com

Assiut University Email: www.aun.edu.eg

\section{ABSTRACT}

Received at: 17/2/2015

Accepted: 26/3/2015
The present study is to investigate the immunological effects of different sub-lethal concentrations of ammonia and trails to control these levels on immunological response by using different protexin probiotic concentrations (Enterococcus faecium). Differential leucocytes count, phagocytic activity, phagocytic index, cortisol level, serum total protein, albumin, globulin, Serum bactericidal activity, Serum lysozome activity and disease resistance against challenge with Vibrio alginolyticus were investigated. Three hundred Fish were divided in to ten equal experimental groups. $1^{\text {st }}$ group (control) treated with $0.0 \mathrm{mg} / \mathrm{l}$ ammonium chloride and fed $0.0 \mathrm{~g} / \mathrm{kg}$ feed protexin, The $2^{\text {nd }}, 3^{\text {rd }}, 4^{\text {th }}$ group treated with $1 \mathrm{mg} / \mathrm{l}$ ammonium chloride (Unionized ammonia-Nitrogen $0.01 \mathrm{mg} / \mathrm{l}$ ) and fed $0.1 \mathrm{~g} / \mathrm{kg}$ feed, $0.2 \mathrm{~g} / \mathrm{kg}$ feed, $0.3 \mathrm{~g} / \mathrm{kg}$ feed of commercial probiotic protexin concentrate respectively. The $5^{\text {th }}, 6^{\text {th }}, 7^{\text {th }}$ group treated with $2 \mathrm{mg} / \mathrm{l}$ ammonium chloride (Unionized ammonia-Nitrogen $0.02 \mathrm{mg} / \mathrm{l}$ ) and fed $0.1 \mathrm{~g} / \mathrm{kg}$ feed, $0.2 \mathrm{~g} / \mathrm{kg}$ feed, 0.3 $\mathrm{g} / \mathrm{kg}$ feed of commercial probiotic protexin concentrate respectively. The $8^{\text {th }}, 9^{\text {th }}$, $10^{\text {th }}$ group treated with $3 \mathrm{mg} / 1$ ammonium chloride (Unionized ammonia-Nitrogen $0.03 \mathrm{mg} / \mathrm{l}$ ) and fed $0.1 \mathrm{~g} / \mathrm{kg}$ feed, $0.2 \mathrm{~g} / \mathrm{kg}$ feed, $0.3 \mathrm{~g} / \mathrm{kg}$ feed of commercial probiotic protexin concentrate respectively. Fish fed at $3 \%$ body weight per day for ten weeks. Results showed that protexin supplementation adverse significantly the negative impacts of increasing ammonia concentrations on lymphocytes, phagocytic activity, phagocytic index, Serum total protein and globulin, serum bactericidal activity and serum lysozome activity in all treated groups compared to control. In contrast, neutrophils and albumin/globulin ratio significantly decreased in all treated groups comparing to the control as well as mortality rates after challenging with Vibrio alginolyticus were significantly lower in all treated groups comparing to the control. Results indicated that by increasing the concentration of the protexin probiotic (Enterococcus faecium) results getting better in all examined parameters comparing to control although increasing ammonia concentrations. Best results in the present study were by inclusion of $0.3 \mathrm{gm} / \mathrm{kg}$ feed of protexin probiotic in seabass diet which improve the immune status of seabass to the favor of adverse the stress of increasing the ammonia concentrations.

Keywords: Protexin - Probiotic-Enterococcus faecium-Ammonia control-immune status - European seabass (Dicentrarchus labrax).

\section{INTRODUCTION}

Aquaculture has become an economic activity of great importance around the world. Aquaculture practices demand intensive production in shorter times. Under the conditions of intensive production, aquatic species are subjected to high-stress conditions, increasing the incidence of diseases and causing a decrease in productivity (Patricia et al., 2012). Sea bass is a commercially important euryhaline marine fish species which is intensively cultured in the
Mediterranean area. The first stages of its culture take place in on-shore tanks and the last stages in sea cages. Lately, the potential of rearing sea bass only in tanks, in extremely high stocking densities, has been investigated (Sammouth et al., 2009). Ammonia and urea are the two main nitrogenous products excreted by teleost fish. Ammonia usually representing 75 to $90 \%$ of nitrogenous excretion. The acute and chronic toxicities of ammonia have been extensively reviewed for freshwater species but ammonia toxicity data for marine fish species or salmonids in sea water are relatively scarce (Fivelstad et al., 1995). In seawater, 
ammonia is measured as total ammonia nitrogen (TAN), which represents the sum of UIA-N and NH4+-N. (Lemariéa et al., 2004). Safe levels for growth, usually extrapolated from LC50 data, are reported to range from 0.05 to $0.2 \mathrm{mg} 1-1$ UIA-N (Handy and Poxton, 1993), depending on species, age and environment (oxygen concentration, pH). Sublethal concentrations of ammonia can damage the gills and also impair immune function leading to increased susceptibility to infectious disease. The 0.26-mg 1-1 UIA-N concentration can be considered as a safe long-term limit in seawater for sea bass juveniles (The EFSA Journal, 2008). Probiotics are usually live microorganisms which when administered in adequate amounts confer a health benefits on host. In last few years probiotics became an integral part of the culture practices for promoting growth and disease resistance to procure high production, certain probiotics used as water additives can also play a significant role in decomposition of organic matter, reduction of nitrogen and phosphorus level as well as control of ammonia, nitrite, and hydrogen sulfide (Sha.Ahmadvand et al., 2012). Protexin concentrate contains beneficial probiotics microorganisms (Enterococcus faecium). This product is designed for continuous use to promote efficient digestion and immunity or at times of stress.

The objective of the current study is conducted to investigate the effect of probiotic Enterococcus faecium "protexin" on immunity and survival of cultured sea bass against ammonia stress.

\section{MATERIALS and METHODS}

1. Fish and experimental design: A total of 300 apparently healthy sea bass with an average body weight of $40 \pm 5$ gram were obtained from private farm. Fish were kept in full glass aquaria measuring $(90 \times 45 X 45 \mathrm{~cm})$ and maintained in aerated water at $27^{\circ} \mathrm{c} \pm 1^{\circ} \mathrm{c}, \mathrm{pH} 8.3 \pm 0.3$ and salinity 32 for 7 days prior to use in experiments. The health status was examined throughout the acclimation period during the acclimation fish fed on the pelleted basic diet only contained $45 \%$ protein twice daily. Fish were randomly divided equally to ten experimental groups. Protexin probiotic were used and mixed thoroughly with the prepared basal fish diet during its preparation. Half of the water was changed daily.

Table 1: Outline of the experimental design:

\begin{tabular}{ccccc}
\hline Group & No. & Ammonium chloride & Diet & Protexin $/ \mathrm{kg}$ \\
\hline 1 & 30 & $0.0 \mathrm{mg} / \mathrm{l}$ & Basal diet & 0.0 \\
\hline 2 & 30 & $1 \mathrm{mg} / \mathrm{l}$ & Basal diet & 0.1 \\
\hline 3 & 30 & $1 \mathrm{mg} / 1$ & Basal diet & 0.2 \\
\hline 4 & 30 & $1 \mathrm{mg} / 1$ & Basal diet & 0.3 \\
\hline 5 & 30 & $2 \mathrm{mg} / 1$ & Basal diet & 0.1 \\
\hline 6 & 30 & $2 \mathrm{mg} / 1$ & Basal diet & 0.2 \\
\hline 7 & 30 & $2 \mathrm{mg} / 1$ & Basal diet & 0.3 \\
\hline 8 & 30 & $3 \mathrm{mg} / 1$ & Basal diet & 0.1 \\
\hline 9 & 30 & $3 \mathrm{mg} / 1$ & Basal diet & 0.2 \\
\hline 10 & 30 & $3 \mathrm{mg} / 1$ & Basal diet & 0.3 \\
\hline
\end{tabular}

*Protexin: Commercial probiotic manufactured by International Ltd UK contain per kg: Enterococcus faecium (NCIMB 11181 E1708). Total Viable Count 2x10 ${ }^{12}$ CFU. Ingredients: Dextrose Monohydrate. Protein $0.5 \%$. Oil $2.0 \%$. Fiber $1.0 \%$. Ash Trace

Ammonium chloride $\left(\mathrm{NH}_{4} \mathrm{CL}\right)$, was used as a source of ammonia by dissolving ammonium chloride powder (99.5\% purity) in distilled water.

UIA-N concentrations were calculated from TAN according to $\mathrm{pH}$, temperature and salinity, using the equation of Bower and Bidwell (1978): \% NH3 $=100 /\left[1+10^{(\log \mathrm{Ke}-\mathrm{pH})}\right]$

Where $\log$ ke as equilibrium constant, is obtained from the expression Johanson and Wedberg (1980): Log ke = $(-0.467+0.001135 \mathrm{~S}+2877.9) / \mathrm{T}$

where $\mathrm{Ke}$ is the dissociation constant, $\mathrm{S}\left(\right.$ in $\left._{\mathrm{gl}}{ }^{-1}\right)$ the salinity and $\mathrm{T}$ the temperature $\left({ }^{\circ} \mathrm{K}\right)$

The concentration of the un-ionized ammonia may be obtained from the expression:

$\mathrm{NH} 3=\% \mathrm{NH} 3(\mathrm{NH} 3+\mathrm{NH} 4+)$ 
2. Blood collection: At the zero day, $4^{\text {th }}$ and $8^{\text {th }}$ week of the experiment, $2 \mathrm{ml}$ blood samples/fish via the caudal vessels were collected from 3 fish from each group of the experiment according to (Hawak et al., 1965). One ml of blood was collected with syringe containing anticoagulant (Heparin) and used for differential leucocytes count Lucky (1977) and Schalm (1986) as well as phagocytic assay (Kawahara et al.,1991) and the another $\mathrm{ml}$ of blood used for serum collection for biochemical determination (Lied et al., 1975). Serum total protein was determined according to Doumas et al. (1981). Serum albumin was determined according to Reinhold (1953). Serum globulin was determined by subtract the total serum albumin from total serum protein according to (Coles, 1974 and Khalil, 2000). Albumin/ globulin ratio was determined by division of serum albumin value on serum globulin value according to (Saffinaz, 2001) Determination of cortisol in serum according to (Gilles et al., 1997). Serum bactericidal activity was determined according to (Rainger and Rowley, 1993) and the results were recorded as survival index (SI) (Word Low and Unlles, 1978). Serum lysozome activity was measured with the turbidimetric method described by Engstad et al. (1992). The result was expressed as one unit of lysozyme activity was defined as a reduction in absorbency of $0.001 / \mathrm{min}$.

3. Challenge test: At the 9th week ten fish from each group were bacteriologically tested and determined to be free from bacterial infection, were artificially infected by $\mathrm{I} / \mathrm{p}$ injection with $0.2 \mathrm{ml} /$ fish of culture suspension of pathogenic Vibrio alginolyticus previously adjusted to 104 . Specificity of death was determined by re-isolation of injected bacteria from freshly dead fish during the period of observation (one week) according to Soliman (1988).

\section{Statistical analysis:}

The data were statistically analyzed according to (SAS, 2000).

\section{RESULTS}

The analysis of variance indicated that although increasing ammonia concentration had a significant negative impact on the differential leucocytic count of seabass but protexin significantly improve lymphocytes and in contrary neutrophils significantly decreased in all treated groups comparing to the control but eosinophils and basophiles had no significant (Table 2) and (Fig.1). Best results were in groups fed on diet contain protexin $0.3 \mathrm{gm} . / \mathrm{kg}$ feed followed by groups fed diet contain $0.2 \mathrm{gm} . / \mathrm{kg}$ feed and groups fed on diet contain $0.1 \mathrm{gm}$. $/ \mathrm{kg}$ feed respectively.

Regarding the effect of ammonia on phagocytic activity as well as phagocytic index and cortisol level of seabass (Table 3) and (Fig.2) showed, significant decrease in phagocytic activity and phagocytic index and significant increase in cortisol level of seabass by increasing ammonia concentration in comparison to the control group. Protexin improve the previous picture to the favor of nearly maintain phagocytic activity and phagocytic index and decreasing the increasing of cortisol level with increasing ammonia concentration.

Examination of serum indicated that protexin adverse the negative effects of ammonia on serum total protein, globulin and Albumin /globulin ratio in all treated groups comparing to the control specially at the 8th week. Best results showed in groups fed on diet contain protexin $0.3 \mathrm{gm} . / \mathrm{kg}$ feed (Table 4) and (Fig.3).

Concerning to the effect of protexin supplemented diet on the negative impacts of increasing ammonia concentrations on the serum bactericidal activity as well as serum lysozyme activity among different groups of seabass during experimental period revealed decrease in their activities in all protexin treated groups by increasing ammonia concentrations but their activities still higher comparing to the control. Best results were in in groups fed on diet contain protexin $0.3 \mathrm{gm}$. $/ \mathrm{kg}$ feed (Table 5) and (Fig.4).

Mortalities of seabass challenged with Vibrio alginolyticus were significantly lower in all treated groups than the control but mortalities increased by increasing the ammonia concentrations moreover the lowest mortality percent was recorded in groups fed on diet contain $0.3 \mathrm{gm} . / \mathrm{kg}$ feed of protexin followed by groups fed diet contain $0.2 \mathrm{gm} . / \mathrm{kg}$ feed then groups fed on diet contain $0.1 \mathrm{gm} . / \mathrm{kg}$ feed respectively (Table 6) and (Fig.5). 
Assiut Vet. Med. J. Vol. 61 No. 145 April 2015

Table 2: Effects of different treatments on differential leucocytic counts of sea bass during experimental period:

\begin{tabular}{|c|c|c|c|c|c|c|c|c|}
\hline \multicolumn{2}{|c|}{ Groups } & \multirow{2}{*}{$\begin{array}{l}\mathbf{N} \\
3\end{array}$} & \multirow{2}{*}{$\begin{array}{l}\text { Lymphocytes } \\
62.33 \pm 1.2 \mathrm{a}, \mathrm{c}\end{array}$} & \multirow{2}{*}{$\begin{array}{c}\text { Monocytes } \\
1 \pm 0 \text { b,c }\end{array}$} & \multirow{2}{*}{$\begin{array}{c}\text { Basophils } \\
4.67 \pm 0 \mathrm{~b}\end{array}$} & \multirow{2}{*}{$\begin{array}{c}\text { Eosinophil } \\
8.33 \pm 0.33 \mathrm{a}\end{array}$} & \multirow{2}{*}{$\begin{array}{l}\text { Neutrophils } \\
12.33 \pm 0.33 \mathrm{a}\end{array}$} & \multirow{2}{*}{$\begin{array}{c}\text { Thrombocytes } \\
2.33 \pm 0.33\end{array}$} \\
\hline \multirow{10}{*}{ 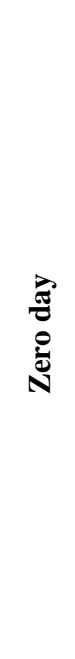 } & G1 & & & & & & & \\
\hline & G2 & 3 & $62.67 \pm 1.33 \mathrm{a}$ & $1 \pm 0 \mathrm{~b}, \mathrm{c}$ & $4 \pm 0 \mathrm{~b}$ & $7.33 \pm 0.33 b, c$ & $13 \pm 0 \mathrm{a}$ & $2.67 \pm 0.33$ \\
\hline & G3 & 3 & $61.67 \pm 0.88 \mathrm{a}, \mathrm{b}$ & $1.33 \pm 0.33 \mathrm{a}, \mathrm{c}$ & $4 \pm 0 \mathrm{~b}$ & $7 \pm 0$ b,c & $14.33 \pm 0.33 \mathrm{a}$ & $2.67 \pm 0.33$ \\
\hline & G4 & 3 & $61.33 \pm 0.33 a, b$ & $1.33 \pm 0.33 \mathrm{a}, \mathrm{c}$ & $6 \pm 0.58 \mathrm{a}$ & $7.67 \pm 0.33 \mathrm{a}, \mathrm{c}, \mathrm{d}$ & $24 \pm 0.58 \mathrm{~b}$ & $2.67 \pm 0.33$ \\
\hline & G5 & 3 & $60.33 \pm 0.33 \mathrm{~b}, \mathrm{c}$ & $1 \pm 0 \mathrm{~b}, \mathrm{c}$ & $4 \pm 0 \mathrm{~b}$ & $7.33 \pm 0.33 \mathrm{~b}, \mathrm{c}, \mathrm{d}, \mathrm{e}$ & $23.33 \pm 0.33 b, c$ & $2.67 \pm 0.33$ \\
\hline & G6 & 3 & $61 \pm 0.58 \mathrm{a}, \mathrm{b}$ & $1.67 \pm 0.33 \mathrm{a}, \mathrm{c}$ & $4.33 \pm 0 \mathrm{~b}$ & $7.67 \pm 0.33 \mathrm{a}, \mathrm{c}$ & $21.67 \pm 1.67 \mathrm{c}, \mathrm{d}$ & $2.33 \pm 0.33$ \\
\hline & G7 & 3 & $62 \pm 0 \mathrm{a}, \mathrm{b}$ & $1.33 \pm 0.33 \mathrm{a}, \mathrm{c}$ & $5.67 \pm 0.33 \mathrm{a}$ & $7.67 \pm 0.33 \mathrm{a}, \mathrm{c}$ & $21.67 \pm 0.88 \mathrm{c}, \mathrm{e}$ & $2.33 \pm 0.33$ \\
\hline & G8 & 3 & $61 \pm 0.58 \mathrm{a}, \mathrm{b}$ & $1 \pm 0 \mathrm{~b}, \mathrm{c}$ & $4 \pm 0 \mathrm{~b}$ & $6.67 \pm 0.33 \mathrm{~b}, \mathrm{e}$ & $23 \pm 0.58 \mathrm{~b}, \mathrm{~d}, \mathrm{e}$ & $2.67 \pm 0.33$ \\
\hline & G9 & 3 & $60 \pm 0 \mathrm{~b}$ & $1.67 \pm 0.33 \mathrm{a}, \mathrm{c}$ & $4 \pm 0 \mathrm{~b}$ & $6.67 \pm 0.33 \mathrm{~b}, \mathrm{e}$ & $24 \pm 0.58 \mathrm{~b}$ & $2.67 \pm 0.33$ \\
\hline & G10 & 3 & $61.33 \pm 0.88 \mathrm{a}, \mathrm{b}$ & $2 \pm 0 \mathrm{a}$ & $5.67 \pm 0.33 \mathrm{a}$ & $6.67 \pm 0.33 \mathrm{~b}, \mathrm{e}$ & $23 \pm 0 b, d, e$ & $2.67 \pm 0.33$ \\
\hline \multirow{10}{*}{ 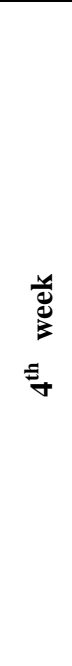 } & G1 & 3 & $62 \pm 0.58 \mathrm{e}$ & $1 \pm 0 \mathrm{~b}$ & $5.33 \pm 0.33 \mathrm{a}, \mathrm{b}$ & $7 \pm 0.58 \mathrm{a}, \mathrm{b}$ & $12.67 \pm 0.33 \mathrm{c}$ & $2 \pm 0 \mathrm{~b}$ \\
\hline & $\mathrm{G} 2$ & 3 & $63.67 \pm 0.88 \mathrm{c}, \mathrm{d}$ & $1 \pm 0 \mathrm{~b}$ & $6 \pm 0 \mathrm{a}$ & $6.33 \pm 0.33 b, c$ & $15.33 \pm 0.33 \mathrm{~b}$ & $3 \pm 0 \mathrm{a}$ \\
\hline & G3 & 3 & $64.67 \pm 0.33 \mathrm{c}$ & $1 \pm 0 \mathrm{~b}$ & $5.67 \pm 0.33 \mathrm{a}, \mathrm{b}$ & $7.33 \pm 0.33 \mathrm{a}$ & $15 \pm 0.58 \mathrm{~b}$ & $3 \pm 0 \mathrm{a}$ \\
\hline & G4 & 3 & $66.33 \pm 0.33 \mathrm{~b}$ & $1.67 \pm 0.33 \mathrm{a}, \mathrm{b}$ & $5 \pm 0 \mathrm{~b}$ & $7.33 \pm 0.33 \mathrm{a}$ & $21 \pm 0.58 \mathrm{a}$ & $3 \pm 0 \mathrm{a}$ \\
\hline & G5 & 3 & $62.67 \pm 0.33 \mathrm{~d}, \mathrm{e}$ & $1.33 \pm 0.33 \mathrm{a}, \mathrm{b}$ & $5.67 \pm 0.33 \mathrm{a}, \mathrm{b}$ & $5.67 \pm 0.33 \mathrm{c}$ & $15.67 \pm 0.67 \mathrm{~b}$ & $3 \pm 0 \mathrm{a}$ \\
\hline & G6 & 3 & $64.67 \pm 0.33 \mathrm{c}$ & $1.33 \pm 0.33 \mathrm{a}, \mathrm{b}$ & $5 \pm 0 \mathrm{~b}$ & $7 \pm 0 \mathrm{a}, \mathrm{b}$ & $12.33 \pm 0.33 \mathrm{c}$ & $3 \pm 0 \mathrm{a}$ \\
\hline & G7 & 3 & $64.67 \pm 0.88 \mathrm{c}$ & $1.67 \pm 0.33 \mathrm{a}, \mathrm{b}$ & $5 \pm 0 \mathrm{~b}$ & $7 \pm 0$ a,b & $20.67 \pm 0.67 \mathrm{a}$ & $3 \pm 0 \mathrm{a}$ \\
\hline & G8 & 3 & $66.33 \pm 0.33 \mathrm{~b}$ & $2 \pm 0.58 \mathrm{a}$ & $6 \pm 0 \mathrm{a}$ & $6.67 \pm 0.33 \mathrm{a}, \mathrm{b}$ & $15 \pm 0.58 \mathrm{~b}$ & $2.33 \pm 0.33 \mathrm{~b}$ \\
\hline & G9 & 3 & $67.0 .33 \mathrm{a}, \mathrm{b}$ & $1 \pm 0 \mathrm{~b}$ & $6 \pm 0.58 \mathrm{a}$ & $7 \pm 0 \mathrm{a}, \mathrm{b}$ & $12.67 \pm 0.33 \mathrm{c}$ & $2.33 \pm 0.33 \mathrm{~b}$ \\
\hline & G10 & 3 & $68.67 \pm 0.33 \mathrm{a}$ & $1.67 \pm 0.33 \mathrm{a}, \mathrm{b}$ & $5.33 \pm 0.33 a, b$ & $7.33 \pm 0.33 \mathrm{a}$ & $21 \pm 1$ a & $2.33 \pm 0.33 \mathrm{~b}$ \\
\hline \multirow{10}{*}{$\begin{array}{l}\bar{d} \\
\vdots \\
\vdots \\
\vdots\end{array}$} & G1 & 3 & $61 \pm 1 \mathrm{~g}$ & $1.33 \pm 0.33 \mathrm{~b}$ & $6.33 \pm 0.33 \mathrm{a}, \mathrm{b}$ & $7 \pm 0$ b,c,d,e & $13.33 \pm 0 \mathrm{c}$ & $3 \pm 0 \mathrm{c}$ \\
\hline & $\mathrm{G} 2$ & 3 & $66.67 \pm 0.33 \mathrm{f}$ & $1.33 \pm 0.33 \mathrm{~b}$ & $6.67 \pm 0.33 \mathrm{a}, \mathrm{b}$ & $7.33 \pm 0.33 \mathrm{a}, \mathrm{c}$ & $13.67 \pm 0.88 \mathrm{c}$ & $3 \pm 0 c$ \\
\hline & G3 & 3 & $68.67 \pm 0.33 \mathrm{~d}, \mathrm{e}$ & $1.67 \pm 0.67 \mathrm{~b}$ & $6 \pm 0 \mathrm{~b}, \mathrm{~d}$ & $7.67 \pm 0.33 \mathrm{a}, \mathrm{b}, \mathrm{d}$ & $16.67 \pm 0.88 \mathrm{~b}$ & $3.33 \pm 0.33 \mathrm{~b}, \mathrm{c}$ \\
\hline & G4 & 3 & $70 \pm 0.58 \mathrm{c}, \mathrm{d}$ & $1 \pm 0 \mathrm{~b}$ & $6 \pm 0.58 \mathrm{~b}, \mathrm{c}$ & $7 \pm 0$ b,c,f & $21 \pm 0.58 \mathrm{a}$ & $3.67 \pm 0.33 \mathrm{a}, \mathrm{b}$ \\
\hline & G5 & 3 & $68.33 \pm 0.33 \mathrm{e}$ & $1.67 \pm 0.33 \mathrm{~b}$ & $7 \pm 0 \mathrm{a}$ & $7 \pm 0$ b,c,g & $11 \pm 0 \mathrm{~d}$ & $3 \pm 0 \mathrm{c}$ \\
\hline & G6 & 3 & $71.33 \pm 0.33 \mathrm{~b}, \mathrm{c}$ & $1.67 \pm 0.67 \mathrm{~b}$ & $6 \pm 0 \mathrm{~b}, \mathrm{e}$ & $8 \pm 0 \mathrm{a}$ & $7 \pm 0 \mathrm{e}$ & $4 \pm 0 \mathrm{a}$ \\
\hline & G7 & 3 & $73.67 \pm 0.33 \mathrm{a}$ & $1.33 \pm 0.33 \mathrm{~b}$ & $6.33 \pm 0 \mathrm{a}, \mathrm{b}$ & $6.67 \pm 0.33 \mathrm{c}, \mathrm{h}$ & $15.67 \pm 1.2 \mathrm{~b}$ & $4 \pm 0 \mathrm{a}$ \\
\hline & G8 & 3 & $68 \pm 0$ e,f & $2 \pm 0 a, b$ & $6.33 \pm 0.33 a, b$ & $\begin{array}{c}6.33 \pm 0.33 \\
\mathrm{e}, \mathrm{f}, \mathrm{g}, \mathrm{h}, \mathrm{i}\end{array}$ & $10.33 \pm 0.58 \mathrm{~d}$ & $3 \pm 0 c$ \\
\hline & G9 & 3 & $70.33 \pm 0.33 \mathrm{c}$ & $3 \pm 0$ a & $5.33 \pm 0 \mathrm{c}, \mathrm{d}, \mathrm{e}$ & $\begin{array}{c}7.33 \pm 0.33 \\
\mathrm{a}, \mathrm{d}, \mathrm{f}, \mathrm{g}, \mathrm{i}\end{array}$ & $6.67 \pm 0.33 \mathrm{e}$ & $3.33 \pm 0.33 \mathrm{~b}, \mathrm{c}$ \\
\hline & G10 & 3 & $72.33 \pm 0.33 \mathrm{a}, \mathrm{b}$ & $1 \pm 0 \mathrm{~b}$ & $6.33 \pm 0.33 \mathrm{a}, \mathrm{b}$ & $6.67 \pm 0.33 \mathrm{c}, \mathrm{i}$ & $16.67 \pm 0.88 \mathrm{~b}$ & $3.33 \pm 0.33 \mathrm{~b}, \mathrm{c}$ \\
\hline
\end{tabular}

Means in the same column with the different small litter at the same week are significantly different at $(\mathrm{P} \geq 0.05)$ 
Fig. 1: Differential leucocytic counts of seabass during experimental period
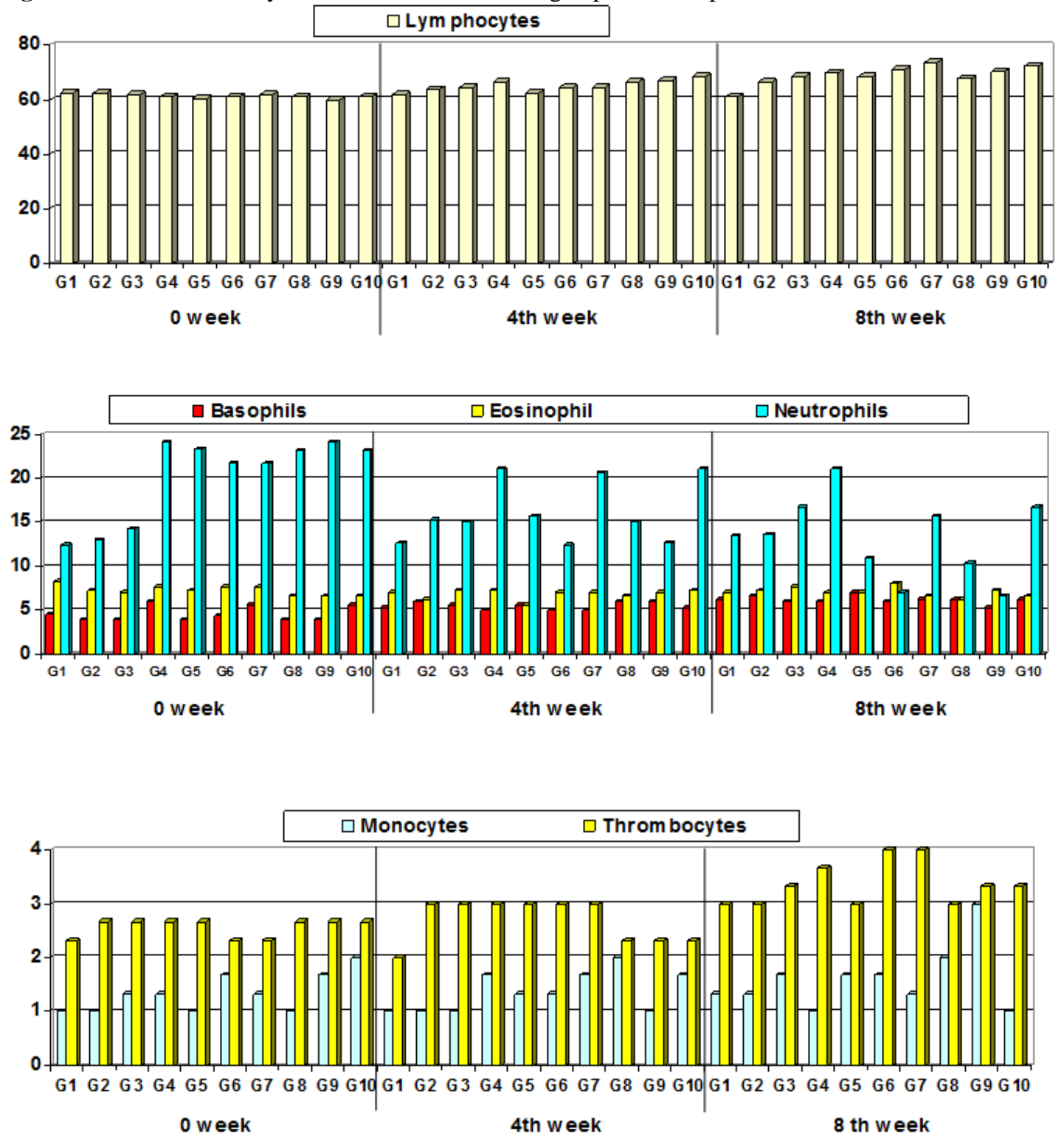

Fig. 2: Cotrisol level, phagocytic activity and phagocytic index of seabass during experimental period.

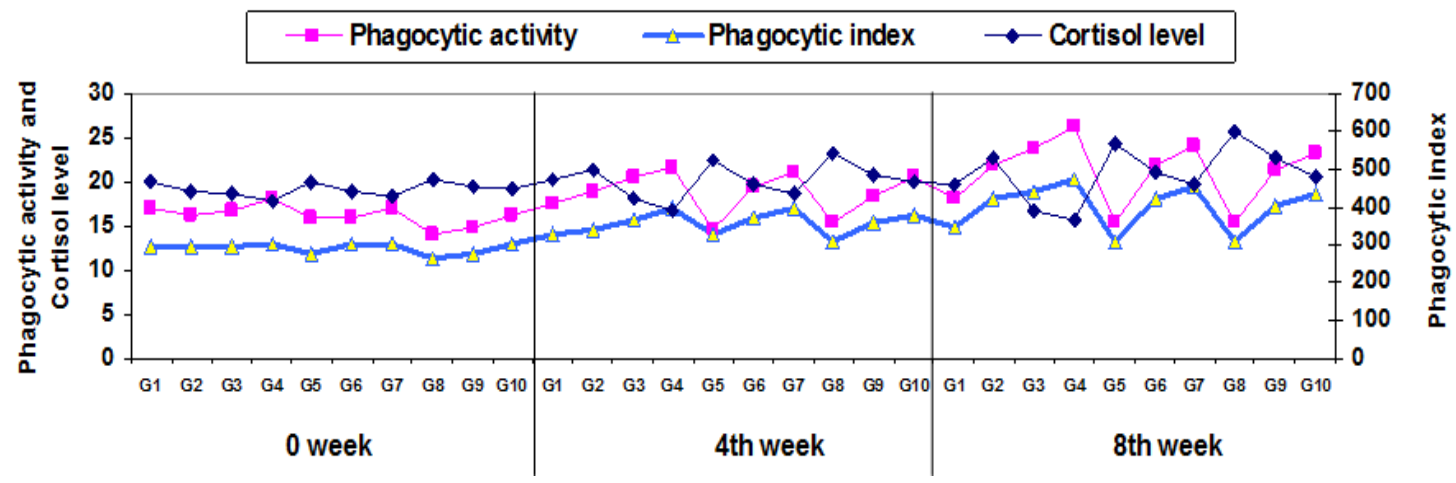




\section{Assiut Vet. Med. J. Vol. 61 No. 145 April 2015}

Table 3: Effects of different treatments on cortisol level, phagocytic activity and phagocytic index of seabass during experimental period:

\begin{tabular}{|c|c|c|c|c|c|}
\hline \multirow{11}{*}{$\begin{array}{l}\vec{E} \\
\stackrel{\Xi}{0} \\
\stackrel{0}{0}\end{array}$} & Groups & $\mathbf{N}$ & Cortisol level & Phagocytic activity & Phagocytic index \\
\hline & G1 & 3 & $468.52 \pm 0.56 b$ & $17 \pm 0 \mathrm{~d}$ & $12.67 \pm 0.33 \mathrm{a}$ \\
\hline & $\mathrm{G} 2$ & 3 & $443.2+1.15 \mathrm{e}$ & $16.33 \pm 0.33 \mathrm{e}, \mathrm{f}$ & $12.67 \pm 0.33 \mathrm{a}$ \\
\hline & G3 & 3 & $434.05 \pm 1.39 \mathrm{f}$ & $16.67 \pm 0.33 \mathrm{~d}, \mathrm{f}$ & $12.67 \pm 0.33 \mathrm{a}$ \\
\hline & G4 & 3 & $418.82 \pm 0.52$ & $18 \pm 0 \mathrm{a}$ & $13 \pm 0 \mathrm{a}$ \\
\hline & G5 & 3 & $468.48 \pm 1.32 \mathrm{~b}$ & $16 \pm 0 \mathrm{e}$ & $12 \pm 0 \mathrm{c}$ \\
\hline & G6 & 3 & $440.93 \pm 1 \mathrm{e}$ & $16 \pm 0 \mathrm{e}$ & $13 \pm 0 \mathrm{a}$ \\
\hline & G7 & 3 & $431 \pm 0.68 \mathrm{~g}$ & $17 \pm 0 \mathrm{~d}$ & $13 \pm 0 \mathrm{a}$ \\
\hline & G8 & 3 & $475.33 \pm 1.59 \mathrm{a}$ & $14 \pm 0 \mathrm{~b}$ & $11.33 \pm 0.33 \mathrm{~b}$ \\
\hline & G9 & 3 & $455.59 \pm 1.12 \mathrm{c}$ & $15 \pm 0 \mathrm{c}$ & $12 \pm 0 \mathrm{c}$ \\
\hline & G10 & 3 & $447.34 \pm 0.81 \mathrm{~d}$ & $16.33 \pm 0.33 \mathrm{e}, \mathrm{f}$ & $13 \pm 0 \mathrm{a}$ \\
\hline \multirow{10}{*}{ 芭 } & G1 & 3 & $470 \pm 3.08 \mathrm{e}$ & $17.67 \pm 0.33 \mathrm{e}$ & $14 \pm 0 \mathrm{f}, \mathrm{g}$ \\
\hline & G2 & 3 & $497.98+0.83 \mathrm{c}$ & $19 \pm 0 \mathrm{c}, \mathrm{d}$ & $14.67 \pm 0.33 \mathrm{e}, \mathrm{f}$ \\
\hline & G3 & 3 & $420.59 \pm 0.89 \mathrm{~h}$ & $20.67 \pm 0.33 \mathrm{~b}$ & $15.67 \pm 0.33 \mathrm{~b}, \mathrm{~d}$ \\
\hline & G4 & 3 & $394.01 \pm 1.17 \mathrm{i}$ & $21.67 \pm 0.33 \mathrm{a}$ & $17 \pm 0 \mathrm{a}$ \\
\hline & G5 & 3 & $526.14 \pm 2.95 \mathrm{~b}$ & $14.67 \pm 0.33 \mathrm{f}$ & $14 \pm 0 \mathrm{f}, \mathrm{g}$ \\
\hline & G6 & 3 & $457.85 \pm 0.79 \mathrm{f}$ & $19.33 \pm 0.33 \mathrm{c}$ & $16 \pm 0 \mathrm{~b}, \mathrm{c}$ \\
\hline & G7 & 3 & $434.03 \pm 1.06 \mathrm{~g}$ & $21 \pm 0 \mathrm{a}, \mathrm{b}$ & $17 \pm 0 \mathrm{a}$ \\
\hline & G8 & 3 & $542.64+1.33 \mathrm{a}$ & $15.33 \pm 0.33 \mathrm{f}$ & $13.33 \pm 0.33 \mathrm{~g}$ \\
\hline & G9 & 3 & $485.89 \pm 2.35 \mathrm{~d}$ & $18.33 \pm 0.33 \mathrm{~d}, \mathrm{e}$ & $15.33 \pm 0.33 \mathrm{c}, \mathrm{d}, \mathrm{e}, \mathrm{f}$ \\
\hline & G10 & 3 & $466.66 \pm 2.69 \mathrm{e}$ & $20.67 \pm 0.33 \mathrm{~b}$ & $16.33 \pm 0.33 \mathrm{a}, \mathrm{b}$ \\
\hline \multirow{10}{*}{ 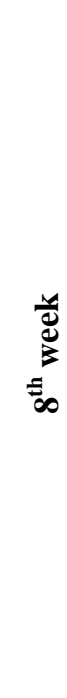 } & G1 & 3 & $459.23 \pm 1.05 \mathrm{~g}$ & $18 \pm 0 \mathrm{e}$ & $15 \pm 0 \mathrm{e}$ \\
\hline & $\mathrm{G} 2$ & 3 & $532.41 \pm 1.89 \mathrm{c}$ & $22 \pm 0 \mathrm{c}, \mathrm{d}$ & $18 \pm 0 \mathrm{c}, \mathrm{d}$ \\
\hline & G3 & 3 & $392.78 \pm 1.28 \mathrm{~h}$ & $23.67 \pm 0.33 \mathrm{~b}$ & $19 \pm 0 \mathrm{~b}$ \\
\hline & G4 & 3 & $364.53+1.42 \mathrm{i}$ & $26.33 \pm 0.33 \mathrm{a}$ & $20.33 \pm 0.33 \mathrm{a}$ \\
\hline & G5 & 3 & $570.04 \pm 0.58 \mathrm{~b}$ & $15.33 \pm 0.33 \mathrm{f}$ & $13.33 \pm 0.33 \mathrm{f}$ \\
\hline & G6 & 3 & $494.14 \pm 0.52 \mathrm{e}$ & $22 \pm 0 \mathrm{c}, \mathrm{d}$ & $18 \pm 0 \mathrm{c}$ \\
\hline & G7 & 3 & $457.73 \pm 1.7 \mathrm{~g}$ & $24 \pm 0 \mathrm{~b}$ & $19.33 \pm 0.33 b$ \\
\hline & G8 & 3 & $597.22 \pm 1.76 \mathrm{a}$ & $15.33 \pm 0.33 \mathrm{f}$ & $13.33 \pm 0.33 \mathrm{f}$ \\
\hline & G9 & 3 & $526.63 \pm 2.8 \mathrm{~d}$ & $21.33 \pm 0.33 \mathrm{~d}$ & $17.33 \pm 0.33 \mathrm{~d}$ \\
\hline & G10 & 3 & $480.08 \pm 0.25 \mathrm{f}$ & $23.33 \pm 0.33 b, c$ & $18.67 \pm 0.33 b, c$ \\
\hline
\end{tabular}

Means in the same column with the different small litter at the same week are significantly different at $(\mathrm{P} \geq 0.05)$ 
Table 4: Effects of different treatments on total serum protein, albumin, globulin and A/G ratio of seabass during experimental period.

\begin{tabular}{|c|c|c|c|c|c|c|}
\hline & Groups & $\mathbf{N}$ & Total protein & Albumin & Globulin & A/G ratio \\
\hline \multirow{10}{*}{ 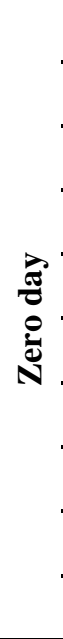 } & G1 & 3 & $4.12 \pm 0.02 \mathrm{~h}$ & $2.14 \pm 0.01 \mathrm{~d}, \mathrm{e}, \mathrm{f}$ & $1.98 \pm 0.01 \mathrm{e}$ & $1.08 \pm 0 \mathrm{a}$ \\
\hline & G2 & 3 & $4.55 \pm 0.01 \mathrm{c}$ & $2.13 \pm 0 \mathrm{e}, \mathrm{g}$ & $2.42 \pm 0.01 \mathrm{~b}$ & $0.88 \pm 0.01 \mathrm{~d}$ \\
\hline & G3 & 3 & $4.59 \pm 0.01 \mathrm{~b}$ & $2.17 \pm 0 \mathrm{c}, \mathrm{e}$ & $2.43 \pm 0.01 \mathrm{~b}$ & $0.89 \pm 0.01 \mathrm{~d}$ \\
\hline & G4 & 3 & $4.89 \pm 0.01 \mathrm{a}$ & $2.2 \pm 0.01 \mathrm{c}$ & $2.69 \pm 0.01 \mathrm{a}$ & $0.82 \pm 0 \mathrm{e}$ \\
\hline & G5 & 3 & $4.35 \pm 0.01 \mathrm{f}$ & $2.05 \pm 0.01 \mathrm{i}$ & $2.3 \pm 0.02 \mathrm{c}$ & $0.89 \pm 0.01 \mathrm{~d}$ \\
\hline & G6 & 3 & $4.47 \pm 0 \mathrm{~d}$ & $2.12 \pm 0.01 \mathrm{f}, \mathrm{g}, \mathrm{h}$ & $2.35 \pm 0.01 \mathrm{c}$ & $0.9 \pm 0.01 \mathrm{~d}$ \\
\hline & G7 & 3 & $4.56 \pm 0.01 \mathrm{~b}, \mathrm{c}$ & $2.23 \pm 0 \mathrm{~b}$ & $2.34 \pm 0.01 \mathrm{c}$ & $0.95 \pm 0 \mathrm{c}$ \\
\hline & G8 & 3 & $4.29 \pm 0.01 \mathrm{~g}$ & $2.1 \pm 0.01 \mathrm{~h}$ & $2.19 \pm 0.01 \mathrm{~d}$ & $0.96 \pm 0 \mathrm{c}$ \\
\hline & G9 & 3 & $4.4 \pm 0.02 \mathrm{e}$ & $2.17 \pm 0.03 \mathrm{c}, \mathrm{d}$ & $2.23 \pm 0.05 \mathrm{~d}$ & $0.97 \pm 0.04 \mathrm{c}$ \\
\hline & G10 & 3 & $4.53 \pm 0.01 \mathrm{c}$ & $2.3 \pm 0.01 \mathrm{a}$ & $2.23 \pm 0.01 \mathrm{~d}$ & $1.03 \pm 0 \mathrm{~b}$ \\
\hline \multirow{10}{*}{ 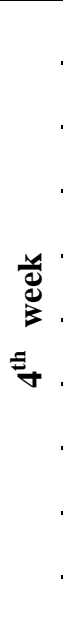 } & G1 & 3 & $4.2 \pm 0.01 \mathrm{f}$ & $2.41 \pm 0.01 \mathrm{~g}$ & $1.79 \pm 0.02 \mathrm{~h}$ & $1.34 \pm 0.02 \mathrm{a}$ \\
\hline & G2 & 3 & $4.39 \pm 0.01 \mathrm{e}$ & $2.25 \pm 0.01 \mathrm{i}$ & $2.14 \pm 0.02 \mathrm{~d}, \mathrm{e}$ & $1.05 \pm 0.01 \mathrm{~g}$ \\
\hline & G3 & 3 & $4.76 \pm 0.03 \mathrm{c}$ & $2.5 \pm 0.01 \mathrm{f}$ & $2.25 \pm 0.04 b, c$ & $1.11 \pm 0.02 \mathrm{e}, \mathrm{f}$ \\
\hline & G4 & 3 & $5.07 \pm 0.02 \mathrm{a}$ & $2.74 \pm 0 \mathrm{a}$ & $2.34 \pm 0.02 \mathrm{a}$ & $1.17 \pm 0.01 \mathrm{~d}$ \\
\hline & G5 & 3 & $4.39 \pm 0.01 \mathrm{e}$ & $2.35 \pm 0.01 \mathrm{~h}$ & $2.04 \pm 0.01 \mathrm{~g}$ & $1.15 \pm 0.01 \mathrm{~d}, \mathrm{f}$ \\
\hline & G6 & 3 & $4.69 \pm 0.01 \mathrm{c}, \mathrm{d}$ & $2.54 \pm 0.01 \mathrm{e}$ & $2.15 \pm 0.01 \mathrm{e}, \mathrm{f}$ & $1.18 \pm 0.01 \mathrm{c}, \mathrm{d}$ \\
\hline & G7 & 3 & $4.92 \pm 0.02 \mathrm{~b}$ & $2.64 \pm 0.03 \mathrm{c}$ & $2.28 \pm 0.04 \mathrm{a}, \mathrm{b}$ & $1.16 \pm 0.03 \mathrm{~d}, \mathrm{e}$ \\
\hline & G8 & 3 & $4.41 \pm 0.04 \mathrm{e}$ & $2.4 \pm 0.01 \mathrm{~g}$ & $2.01 \pm 0.04 \mathrm{~g}$ & $1.19 \pm 0.03 \mathrm{~b}, \mathrm{~d}$ \\
\hline & G9 & 3 & $4.67 \pm 0.02 \mathrm{~d}$ & $2.59 \pm 0.01 \mathrm{~d}$ & $2.09 \pm 0.01 \mathrm{f}, \mathrm{g}$ & $1.24 \pm 0.01 \mathrm{~b}$ \\
\hline & G10 & 3 & $4.88 \pm 0.02 \mathrm{~b}$ & $2.69 \pm 0.01 \mathrm{~b}$ & $2.19 \pm 0.01 \mathrm{c}, \mathrm{d}, \mathrm{f}$ & $1.23 \pm 0 \mathrm{~b}, \mathrm{c}$ \\
\hline \multirow{10}{*}{ 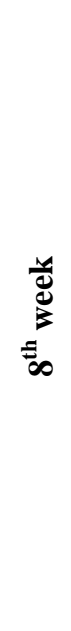 } & G1 & 3 & $4.22 \pm 0.01 \mathrm{~d}$ & $2.2 \pm 0.01 \mathrm{e}, \mathrm{f}$ & $2.02 \pm 0.01 \mathrm{~d}, \mathrm{e}$ & $1.09 \pm 0.01 \mathrm{~b}$ \\
\hline & $\mathrm{G} 2$ & 3 & $4.17 \pm 0.04 \mathrm{~d}$ & $2.14 \pm 0.02 \mathrm{f}, \mathrm{g}$ & $2.02 \pm 0.04 \mathrm{~d}, \mathrm{e}$ & $1.06 \pm 0.02 \mathrm{~b}, \mathrm{~d}$ \\
\hline & G3 & 3 & $5.19 \pm 0.01 \mathrm{~b}$ & $1.79 \pm 0.06 \mathrm{~h}$ & $3.4 \pm 0.07 \mathrm{a}$ & $0.53 \pm 0.03 \mathrm{~g}$ \\
\hline & G4 & 3 & $5.43 \pm 0.03 \mathrm{a}$ & $2.81 \pm 0.02 \mathrm{a}$ & $2.62 \pm 0.04 \mathrm{~b}, \mathrm{c}$ & $1.07 \pm 0.02 \mathrm{~b}, \mathrm{c}$ \\
\hline & G5 & 3 & $4.24 \pm 0.08 \mathrm{~d}$ & $2.12 \pm 0.09 \mathrm{~g}$ & $2.12 \pm 0.09 \mathrm{~d}$ & $1 \pm 0.04 \mathrm{~d}, \mathrm{e}$ \\
\hline & G6 & 3 & $4.91 \pm 0.02 \mathrm{c}$ & $2.32 \pm 0.02 \mathrm{c}, \mathrm{d}$ & $2.59 \pm 0.01 \mathrm{~b}, \mathrm{c}$ & $0.9 \pm 0.01 \mathrm{f}$ \\
\hline & G7 & 3 & $5.18 \pm 0.01 \mathrm{~b}$ & $2.51 \pm 0.01 \mathrm{~b}$ & $2.67 \pm 0.01 \mathrm{~b}$ & $0.94 \pm 0.01 \mathrm{f}$ \\
\hline & G8 & 3 & $4.18 \pm 0.01 \mathrm{~d}$ & $2.26 \pm 0.02 \mathrm{~d}, \mathrm{e}$ & $1.92 \pm 0.01 \mathrm{e}$ & $1.18 \pm 0.02 \mathrm{a}$ \\
\hline & G9 & 3 & $4.9 \pm 0.02 \mathrm{c}$ & $2.38 \pm 0.02 \mathrm{c}$ & $2.51 \pm 0.01 \mathrm{c}$ & $0.95 \pm 0.01 \mathrm{e}, \mathrm{f}$ \\
\hline & G10 & 3 & $5.09 \pm 0.01 \mathrm{~b}$ & $2.57 \pm 0.02 \mathrm{~b}$ & $2.52 \pm 0.03 \mathrm{c}$ & $1.02 \pm 0.02 \mathrm{c}, \mathrm{d}$ \\
\hline
\end{tabular}

Means in the same column with the different small litter at the same week are significantly different at $(\mathrm{P}>0.05)$ 
Fig. 3: Total serum protein, albumin, globulin, and A/G ratio of sea bass during experimental period.

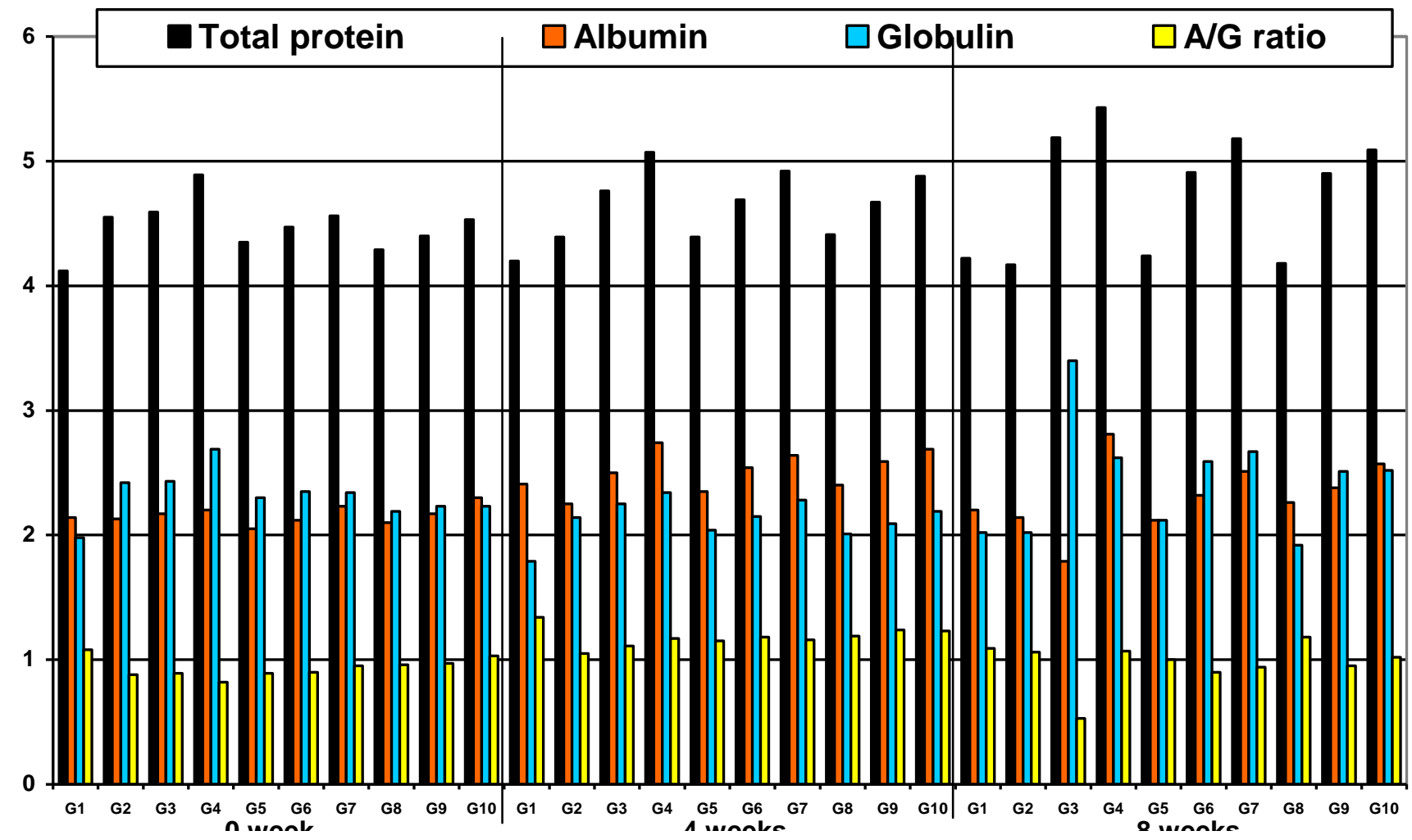

Fig. 4: Serum lysozyme and bactericidal activity of seabass during experimental period

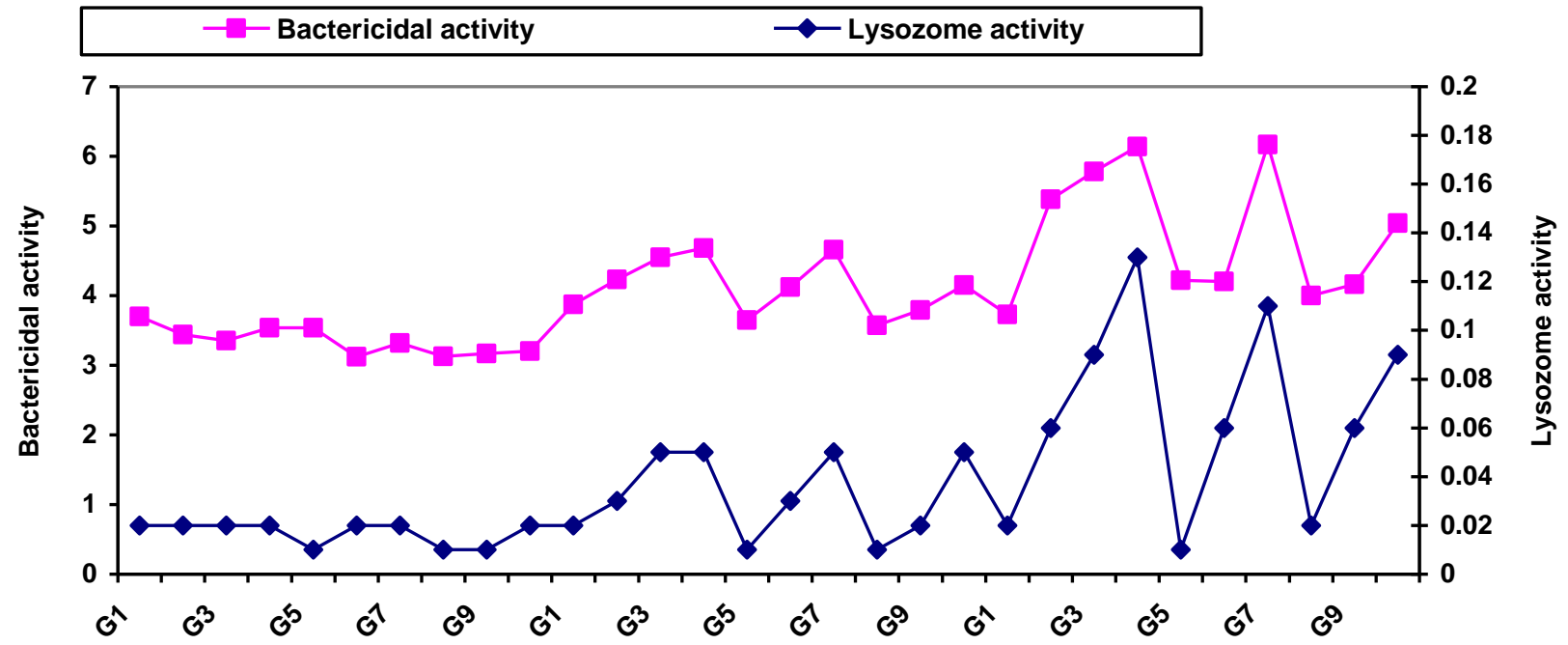


Table 5: Effects of different treatments on serum lysozyme and bactericidal activity of seabass during experimental period:

\begin{tabular}{|c|c|c|c|c|}
\hline \multirow{11}{*}{ 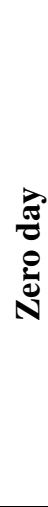 } & Groups & $\mathbf{N}$ & Lysozome activity & Bactericidal activity \\
\hline & G1 & 3 & $0.02 \pm 0 \mathrm{a}$ & $3.7 \pm 0.04 \mathrm{a}$ \\
\hline & G2 & 3 & $0.02 \pm 0 \mathrm{a}$ & $3.44 \pm 0 \mathrm{~b}$ \\
\hline & G3 & 3 & $0.02 \pm 0 \mathrm{a}$ & $3.35 \pm 0.01 \mathrm{c}$ \\
\hline & G4 & 3 & $0.02 \pm 0 \mathrm{a}$ & $3.54+0.05 \mathrm{~d}$ \\
\hline & G5 & 3 & $0.01 \pm 0 \mathrm{~b}$ & $3.54 \pm 0 \mathrm{~d}$ \\
\hline & G6 & 3 & $0.02 \pm 0 \mathrm{a}$ & $3.12 \pm 0 \mathrm{e}$ \\
\hline & G7 & 3 & $0.02 \pm 0 \mathrm{a}$ & $3.32 \pm 0 \mathrm{c}$ \\
\hline & G8 & 3 & $0.01 \pm 0 \mathrm{~b}$ & $3.13 \pm 0.01 \mathrm{e}$ \\
\hline & G9 & 3 & $0.01 \pm 0 \mathrm{~b}$ & $3.17 \pm 0.01 \mathrm{e}, \mathrm{f}$ \\
\hline & G10 & 3 & $0.02 \pm 0 \mathrm{a}$ & $3.2 \pm 0.01 \mathrm{f}$ \\
\hline \multirow{10}{*}{ 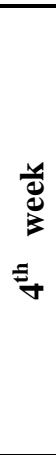 } & G1 & 3 & $0.02+0 \mathrm{c}$ & $3.87 \pm 0 \mathrm{e}$ \\
\hline & G2 & 3 & $0.03 \pm 0 \mathrm{~b}$ & $4.23 \pm 0.01 \mathrm{c}$ \\
\hline & G3 & 3 & $0.05 \pm 0 \mathrm{a}$ & $4.55 \pm 0.01 \mathrm{~b}$ \\
\hline & G4 & 3 & $0.05 \pm 0 \mathrm{a}$ & $4.68 \pm 0.01 \mathrm{a}$ \\
\hline & G5 & 3 & $0.01 \pm 0 \mathrm{~d}$ & $3.65 \pm 0.01 \mathrm{~g}$ \\
\hline & G6 & 3 & $0.03 \pm 0 \mathrm{~b}$ & $4.12 \pm 0.01 \mathrm{~d}$ \\
\hline & G7 & 3 & $0.05 \pm 0 \mathrm{a}$ & $4.66 \pm 0.01 \mathrm{a}$ \\
\hline & G8 & 3 & $0.01 \pm 0 \mathrm{~d}$ & $3.57 \pm 0.01 \mathrm{~h}$ \\
\hline & G9 & 3 & $0.02+0 \mathrm{c}$ & $3.79 \pm 0.01 \mathrm{f}$ \\
\hline & G10 & 3 & $0.05 \pm 0 \mathrm{a}$ & $4.15 \pm 0.01 \mathrm{~d}$ \\
\hline \multirow{10}{*}{ 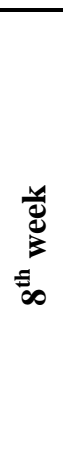 } & G1 & 3 & $0.02 \pm 0 \mathrm{e}$ & $3.73 \pm 0.03 \mathrm{~h}$ \\
\hline & G2 & 3 & $0.06+0 \mathrm{~d}$ & $5.38 \pm 0.03 \mathrm{~d}$ \\
\hline & G3 & 3 & $0.09 \pm 0 \mathrm{c}$ & $5.78 \pm 0.03 \mathrm{c}$ \\
\hline & G4 & 3 & $0.13 \pm 0 \mathrm{a}$ & $6.14 \pm 0.01 \mathrm{~b}$ \\
\hline & G5 & 3 & $0.01 \pm 0 \mathrm{f}$ & $4.22 \pm 0.01 \mathrm{f}$ \\
\hline & G6 & 3 & $0.06+0 \mathrm{~d}$ & $4.2+0.01 \mathrm{f}$ \\
\hline & G7 & 3 & $0.11 \pm 0 \mathrm{~b}$ & $6.17 \pm 0.03 \mathrm{a}$ \\
\hline & G8 & 3 & $0.02 \pm 0 \mathrm{e}$ & $4 \pm 0.02 \mathrm{~g}$ \\
\hline & G9 & 3 & $0.06 \pm 0 \mathrm{~d}$ & $4.16 \pm 0.01 \mathrm{f}$ \\
\hline & G10 & 3 & $0.09 \pm 0 \mathrm{c}$ & $5.04 \pm 0.04 \mathrm{e}$ \\
\hline
\end{tabular}

Means in the same column with the different small litter at the same week are significantly different at $(\mathrm{P} \geq 0.05)$.

Table 6: Effects of different treatments on mortality percent of seabass after challenge with Vibrio alginolyticus

Group

$\mathbf{N}$

Mortalities

\section{Protected}

Number of fish

\begin{tabular}{cccc}
\hline 1 & 10 & 10 & 100 \\
\hline 2 & 10 & 6 & 60 \\
\hline 3 & 10 & 4 & 40 \\
\hline 4 & 10 & 1 & 10 \\
\hline 5 & 10 & 9 & 90 \\
\hline 6 & 10 & 7 & 70 \\
\hline 7 & 10 & 3 & 90 \\
\hline 8 & 10 & 9 & 80 \\
\hline 9 & 10 & 8 & 50
\end{tabular}

Number of fish

\begin{tabular}{lll}
00 & 0 & 0 \\
\hline 60 & 2 & 20 \\
\hline 40 & 6 & 60 \\
10 & 9 & 90 \\
\hline 90 & 1 & 10 \\
\hline 70 & 3 & 30 \\
\hline 30 & 7 & 70 \\
\hline 90 & 1 & 10 \\
\hline 80 & 2 & 20 \\
\hline 50 & 5 & 50 \\
\hline
\end{tabular}


Fig. 5: Mortality percent of seabass after challenge with Vibrio alginolyticus

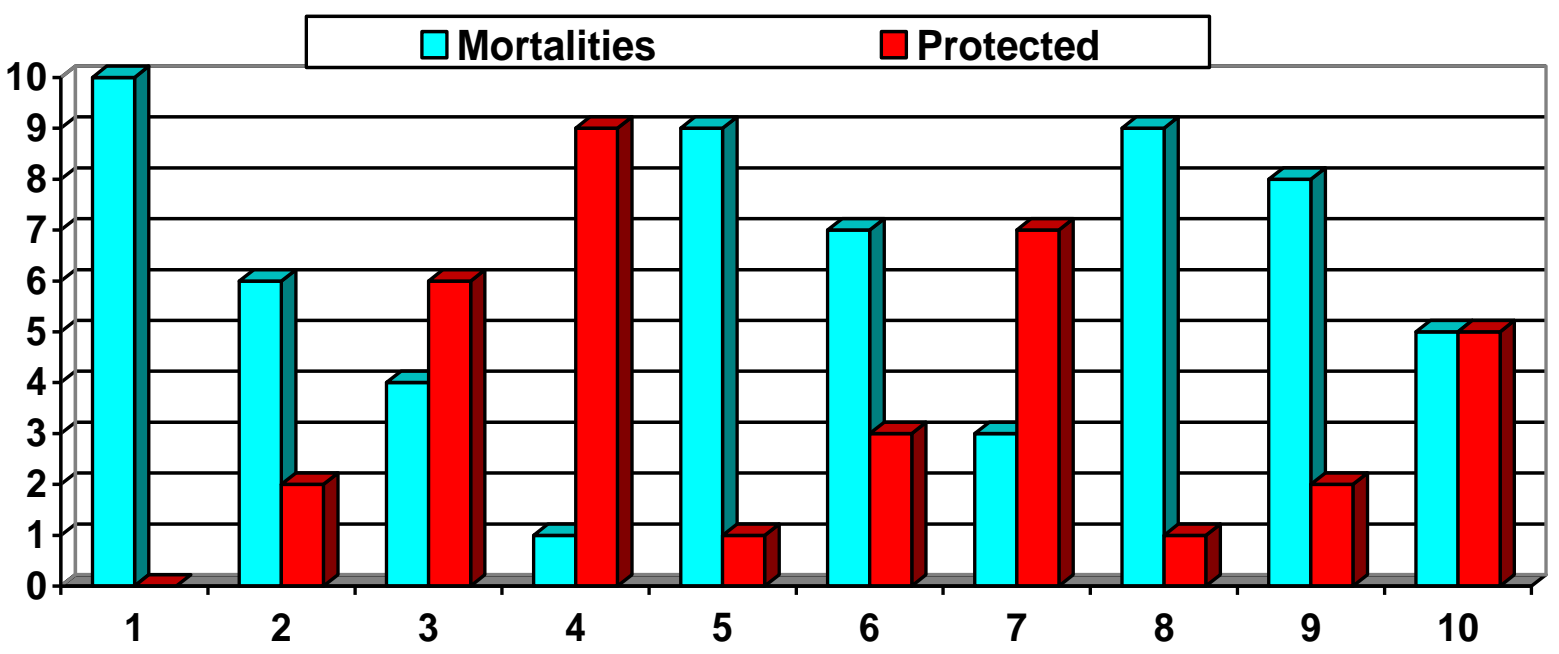

\section{DISCUSSION}

Ammonia exposure may act as a stressor and induce some adaptive endocrine responses and complex metabolic adaptations (Mommsen et al., 1999). Fish experiencing stress show a number of physiological changes that are expressed through a number of particular indicators.

In general stress affects aquatics through weakening immune system (Mahshid and Leila, 2013).

A lot of bacterial cultures containing nitrifying bacteria to control the ammonia level in culture water are available commercially. Nitrifies are responsible for the oxidation of ammonia to nitrite and subsequently to nitrate (Asaad et al., 2013).

Some Lactic acid bacteria (LAB) have proven to be very useful probiotics in different animals including fish / shellfish. The promising probiotic strains of LAB include the members of genera Lactobacillus, Lactococcus and Enterococcus from the representative species Enterococcus faecium (E.faecium). Similarly LAB can improve haematological indices such as hemoglobin concentration, haematocrit percentage, total erythrocytes counts, total leucocytes counts, total serum protein, globulin, glucose, and cholesterol level in fish. Several immunological studies have confirmed the ability of some LAB to stimulate fish immune systems and have been found to elevate several immunological parameters like phagocytic activity, lysozyme level, peroxidase/anti-peroxidase level, complement activity and respiratory burst activity in teleosts (Sukanta, 2013).

Haematological and biochemical parameters have been acknowledged as valuable tools for monitoring fish health.

The results indicated that although increasing ammonia concentration had a significant negative impact on the differential leucocytic count but protexin significantly improve lymphocytes and incontrary neutrophils significantly decreased in all treated groups comparing to the control. These findings were nearly obtained by Manal A. A. Essa et al. (2012) after supplementation of E.faecium in the diet of Oreochromis niloticus but without using ammonia as stress.

The present study showed, significant decrease in phagocytic activity and phagocytic index; similar results were obained by Winton et al. (2004) where ammonia caused a depression in immune Parameters as phagocytic activity of $H$. diversicolor supertexta but Protexin improve the previous picture to the favor of nearly maintain phagocytic activity and phagocytic index as the control group these results nearly supported by (Sukanta, 2013).

It is well known that cortisol plays an adaptive function against stressors. However, chronically elevated cortisol levels may become damaging for several physiological functions e.g. suppression of the immune system (Person et al., 2003). In the present study, serum cortisol was measured as an indicator of primary stress response. The analysis of serum cortisol levels carried out in this study gave the evidence that the groups fed with protexin showed a better tolerance to ammonia as stress rearing conditions. This was evidenced by the lower cortisol levels detected in the treated experimental groups with comparing to control nearly these results were supported by (Carnevali and Sulpizio 2006) where cortisol levels obtained in the probiotic treated European seabass juveniles (Dicentrarchus labrax,L.), fishes were significantly lower than those in the control that untreated with probiotic.

With increasing concentration of Total Ammonia Nitrogen (TAN), haemoglobin and serum protein content were reduced in mrigal (Cirrhinus mrigala) (Hamilton) (Das et al., 2004) similar results were observed in the present study but with increasing protexin concentration in seabass feed the serum total 
proteins as well as total globulin levels were significantly improved in all treated groups than the control. Similar results were also obtained after E.faecium supplementation in the diet of O.niloticus by Manal A. A. Essa et al. (2012) but without using ammonia as stress.

Lysozyme, being an enzyme with antibacterial activity, can split peptidoglycan in bacterial cell walls especially of the gram positive species and can cause lysis of the cells. The Lysozyme increased with activation of immune system.

The present study revealed decreasing lysozyme activity as well as Bactericidal activity during the experimental period in all treated groups by increasing ammonia concentrations but using Enterococcus faecium relatively improve this picture to be better than the control, These results supported by Kim et al. (2012) in investigation of the effect of a probiotic, Enterococcus faecium, on olive flounder (Paralichthys olivaceus) moreover also (Taoka et al., 2006) showed that viable probiotics administered to Japanese flounder (Paralichthys olivaceus), increased nonspecific immune response, determined by parameters such as lysozyme activity, neutrophil migration and bactericidal activity, which improved the resistance of fish to infection. On contrary, dietary supplementation of probiotics like Enterococcus faecium in O.niloticus failed to elevate lysozyme level (Wang et al., 2008) and (Zhou et al., 2009). This is may be due to different fish species and water.

Concerning mortalities of ammonia stressed seabass challenged with Vibrio alginolyticus were significantly lower in all treated groups than the control but mortalities increased by increasing the ammonia concentrations moreover the lowest mortality percent was recorded in groups fed on diet contain $0.3 \mathrm{gm} . / \mathrm{kg}$ feed of protexin. These results supported by Liu and Chen (2004) as well as Cheng et al. (2004) and (Winton et al., 2004) where ammonia in water caused a depression in the immune response and an increase in mortality of Litopenaeus vannamei from the $V$. alginolyticus infection and mortality of $H$. diversicolor supertexta from $V$. parahaemolyticus respectively. The obtained results in the present study may be attributed to that ammonia caused suppression of the cellular or the non-specific defense mechanisms or to the effect of ammonia on other physiological systems (vascular, respiratory, etc.) Hurvitz et al. (1997) where studying the effect of sublethal concentrations of ammonia on rainbow trout (Oncorhynchus mykiss Walbaum), vaccinated against and challenged with Streptococcus iniae survival and the antibody response referred decreasing of protection against $S$. iniae in ammonia-exposed trout. Inclusion of protexin in seabass feeding have positively impacted the resistance of fish to Vibrio alginolyticus infection as was indicated by significantly lower mortality rates of the ammonia treated fish challenged by Vibrio alginolyticus in comparison to the control. These results were supported by Krummenauer et al. (2009) after dietary application of E.faecium to shrimp challenged by Vibrio parahaemolyticus as well as Gopalakannan and Arul (2011) after challenging E.faecium MC13 supplemented Cyprinus carpio by Aeromonas hydrophila.

\section{CONCLUSION}

It could be concluded that supplementation of protexin (Enterococcus faecium) as probiotic in seabass feeding have positively impacted the resistance of fish to stress (sub-lethal concentrations of ammonia) as was indicated by significant increasing of lymphocytes, total protein, globulin, phagocytic activity, index of phagocytes, lysozyme activity and bactericidal activity which enhanced the resistance of challenged fish to Vibrio alginolyticus as was indicated by significant decrease in mortalities rates in protexin treated groups than the control. The highest dietary level $0.3 \mathrm{gm}$. $/ \mathrm{kg}$ feed of protexin showed best results than $0.2 \mathrm{gm} . / \mathrm{kg}$ feed then 0.1 $\mathrm{gm} . / \mathrm{kg}$ feed. For seabass ammonia stress tolerance Enterococcus faecium supplement should be recommended.

\section{REFERENCES}

Asaad, H. Mohamed; Rex, FM. Traifalgar; Augusto, E. and Serrano, Jr. (2013): Assessment of Probiotic Application on Natural Food, Water Quality and Growth Performance of Saline Tilapia Oreochromis mossambicus L. Cultured in Concrete Tanks. Fisheries and Aquaculture Journal, Vol. 2013: FAJ-75.

Bower, CE. and Bidwell, JP. (1978): Ionization of ammonia in seawater: effects of temperature, $\mathrm{pH}$ and salinity. J. Fish. Res. Board Can. 35: 1012-1016.

Carnevali, L. de Vivo and R. Sulpizio. (2006): Growth improvement by probiotic in European seabass juveniles (Dicentrarchus labrax, L.), with particular attention to $\mathrm{IGF}_{1}$, myostatin and cortisol gene expression. Aquaculture, vol.258, no.1-4, pp. 430-438.

Cheng, W.; Hsiao, IS. and Chen, JC. (2004): Effect of ammonia on the immune response of Taiwan abalone (Haliotis diversicolor supertexta) and its susceptibility to Vibrio parahaemolyticus. Fish \& Shellfish Immunol. 17(3): 193-202.

Coles, E.H. (1974): Veterinary Clinical Pathology. PP.211-213. W.B. Sounder's company, Philadelphia, London, Toronto.

Das, P.C.; Ayyappan, S.; Jena, J.K. and Das, B.K. (2004): Acute toxicity of ammonia and its sublethal effects on selected haematological and enzymatic parameters of mrigal, Cirrhinus mrigala (Hamilton). Aquaculture Research,V. 35, 2, 134-143. 
Doumas, B.T.; Bayso, D.D.; Carter, R.J.; Peters, T. and Schaffer, R. (1981): Determination of total serum protein. Clin. Chem., 27: 1642-1643.

Engstad, R.E.; Robertson, B. and Frivold, E. (1992): Yeast glucan induces increase in activity of lysozyme and complement mediated haemolytic activity in Atlantic salmon blood. Fish \& Shellfish Immunol. 2: 287-297.

The EFSA Journal (2008): Scientific Opinion of the Panel on Animal Health and Welfare on a request from the European Commission on animal welfare aspects of husbandry systems for farmed European sea bass and Gilthead sea bream. 844, 1-21.

Fivelstad, S.; Schwarz, J. and Stromsnes, H. (1995): Sublethal effects and safe levels of ammonia in seawater for Atlantic salmon post molts (Salmo salar L.). Aquacult. Eng. 14, 271-280.

Gilles, M.; Ahmed, B.; Ahmed, B.; Micheline, G.; Francoise, D.; Noah, H.; Akram, Al-Halnak; Hany, S.; James, P.G.; Renè, J.; Jean, L.B.; Philippe, B.; Philippe, A.; Jean-Marie, V.; Andrè, P.; Hrvé, G. and Jean, F. (1997): Radioimmunoassay of cortisone in serum, urine, and saliva to assess the status of the cortisol-cortisone shuttle. Clinical chemistry, 43:1397-1407.

Gopalakannan, A. and Arul, V. (2011): Inhibitory activity of probiotic Enterococcus faecium MC13 against Aeromonas hydrophila confers protection against hemorrhagic septicemia in common carp Cyprinus carpio. Aquaculture international, vol. 19. No. 5, pp. 973-985.

Handy, R.D. and Poxton, M.G. (1993): Nitrogen pollution in mariculture: toxicity and excretion of nitrogenous compounds by marine fish. Fish Biol. Fish. 3, 205-241.

Hawak, P.P.; Oscar, B.L. and Summerson, W. (1965): Hawak's physiological chemistry. London J. and A. Churchill Ltd. $14^{\text {th }}$ Ed. HEA Ireland (2002-2005).

Hurvitz, A.; Bercovier, H. and Van-Rijn, J. (1997): Effect of ammonia on the survival and the immune response of rainbow trout (Oncorhynchus mykiss, Walbaum) vaccinated against Streptococcus iniae. Fish\&ShellfishImmunol. Vol. 7, No. 1, pp. 45-53.

Johansson, $O$. and Wedberg, M. (1980): The ammonia-ammonium equilibrium in seawater at temperatures between 2 and $25{ }^{\circ} \mathrm{C}$. J. Solu. Chem. 9: 37-44.

Kawahara, E.; Ueda, T. and Nomura, S. (1991): In vitro phagocytic activity of White spotted shark cells after injection with Aeromonas salmonicida extracellular products. Gyobyo Kenkyu, Japan, 26 (4): 213-214.

Khalil, R.H. (2000): Streptococcosis as a cause of massive mortalities among Nile Tilapia (Oreochromis niloticus). $9^{\text {th }}$ Sci. Cong. Fac. Vet. Med., Assiut Univ., Egypt. 366-377.
Kim, YR.; Kim, EY.; Choi, SY.; Hossain, MT.; Oh, R.; Heo, WS.; Lee, JM.; Cho, YC. and Kong, IS. (2012): Effect of a probiotic strain, Enterococcus faecium, on the immune responses of olive flounder (Paralichthys olivaceus). J. Microbiol Biotechnol.; 22(4): 526-9.

Krummenauer, D.; Abreu, PC.; Lara, G.; Poersch, L.; Encarnacao, P. and Wasielesky, Jr W. (2009): The effect of probiotic in Litopenaeus vannamei bio-floc technology culture system contaminated with Vibrio parahaemolyticus. Abstract World Aquaculture conference, Mexico.

Lemarié, G.; Dosdata, A.; Covèsa, D.; Duttoa, G.; Gasseta, E. and Person-Le Ruyetb, J. (2004): Effect of chronic ammonia exposure on growth of European seabass (Dicentrarchus labrax) juveniles. Aquaculture, 229(1-4): 479-491.

Lucky, Z. (1977): Methods for the diagnosis of fish diseases. Ameruno Publishing Co, PVT, Ltd. New Delhi, Bomby, New York.

Lied, E.; Gezerde, Z. and Braskhan, D.R. (1975): Simple and rapid technique for repeated blood sampling in Rainbow trout. J. of Fish RES. Board of Canada, 32 (5): 699-701.; 16(3): 321-34.

Liu, CH. and Chen, JC. (2004): Effect of ammonia on the immune response of white shrimp Litopenaeus vannamei and its susceptibility to Vibrio alginolyticus. Fish \& Shellfish Immunol. 16(3): 321-34.

Mahshid, Rezaei and Leila, Nateghi. (2013): Increasing resistance of larvae of oncorhynchus mykiss to environmental stresses such as temperature and $\mathrm{Ph}$ using the probiotic protexin. Annals of Biological Research, 4 (2): 327-329. (http://scholarsresearchlibrary.com/ archive.html).

Manal A.A. Essa; Mortada M.A.; Mohamed A.A. Abd El-Galil and Fatma M.M. Korni. (2012): Diagnosis and safe prevention of Edwardsiellosis in Oreochromis niloticus. The Global Journal of Fisheries and Aqua. Res. Vol. No. 5, (2012) - ISSN 18191 Proc. of the $5^{\text {th }}$ Global Fisheries \& Aqua. Research Conf., Egypt, (2012) pp. 147-159.

Mommsen, T.P.; Vijayan, M.M. and Moon, T.W. (1999): Cortisol in teleosts: dynamics, mechanisms of action, and metabolic regulation. Reviews in Fish Biology and Fisheries 9: 211-268.

Patricia, M. Cruz; Ana, L.Ibanez; Oscar, A.M. Hermosillo and Hugo, C.R. Saad (2012): Use of probiotics in aquaculture. ISRN microbial: 916-845.

Person, Le Ruyeta, J.; Lamersbc, A.; Le Rouxa, A.; Sévèrea, A.; Boeufad, G. and Mayer-Gostan, N. (2003): Long-term ammonia exposure of 
turbot: effects on plasma parameters Journal of Fish Biology; 62 (4) : 879-894.

Rainger, G.E. and Rowley, A.F. (1993): Antibacterial activity in the serum and mucus of rainbow trout, Oncorhynchus mykiss, following immunization with Aeromonas salmonicida. Fish and shellfish Immunology 3. 475-482.

Reinhold, R.R. (1953): Determination of serum albumen. Clin.Chem. 21: 1370-1372.

Safinaz, G.M.I. (2001): Effect of phenol on the immune response of tilapia fish and susceptibility to disease. Ph.D. Thesis Fac. Of Vet. Med. Suez canal univ.

Sammouth, S.; d'Orbcastel, E.R.; Gasset, E.; Lemarié, G.; Breuil, G.; Marino, G. and Coeurdacier, J.L. (2009): The effect of density on sea bass (Dicentrarchus labrax) performance in a tank-based recirculating system. Aquaculture Engineering, 40(2), 72-78.

SAS. (2000): Statistical analysis system. User's Guide statistics. SAS Institute Cary, North Carolina, USA.

Schalm, O.W. (1986): Veterinary Hematology. $4^{\text {th }}$ Ed., Lea and Fibiger, Philadelphia.

Sha. Ahmadvand; Jafaryan, H.; Farahi, A. and She. Ahmadvand. (2012): Effect of frozen Daphnia magna diet mixed with probiotic protexin on growth and survival of rainbow trout (Onchorhynchus mykiss) fry reared under controlled conditions. Online journal of animal and feed research. Volum2, issue 1, 34-39.
Soliman, M.K. (1988): Studies on Aeromonas hydrophila on some cultured freshwater fish "Oreochromis niloticus". Ph.D. Thesis, Avian and Aquatic Anima. Med., Fac. Of Vet. Med. Alex. Univ.

Sukanta, K. Nayak (2013): Use of lactic acid bacteria in fish farming. Volume XVIII No. 2. ISSN 0859-600X. Aquaculture Asia Research and farming techniques p.25-27.

Taoka, Y.; H. Maeda, J. and Y. Jo. (2006): Growth, stress tolerance and non-specific immune response of Japanese flounder (Paralichthys olivaceus) to probiotics in a closed recirculating system. Fisheries Science, Vol. 72, No. 2, pp. 310-321.

Wang, Y.B.; Zi-Qiang, T.; Jiang-Tao, Y. and Wei-fen, L. $(2008$ b): Effect of probiotics, Enteroccus faecium, on tilapia (Oreochromis niloticus) growth performance and immune response. Aquaculture 27, 203-207.

Winton, C.; I-Shan, H. and Jiann-Chu, C. (2004): Effect of ammonia on the immune response of Taiwan abalone (Haliotis diversicolor supertexta) and its susceptibility to Vibrio parahaemolyticus. Fish \& Shellfish Immunology 17; 193-202 .

Zhou, X.; Tian, Z.; Wang, Y. and Li, W. (2009): Effect of treatment with probiotics as water additives on tilapia (Oreochromis niloticus) growth performance and immune response. Fish Physiol. Biochem. E 1742:1573 e 5168.

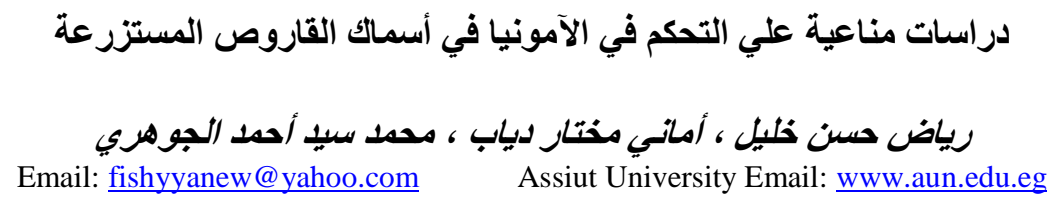

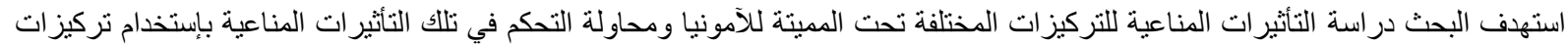

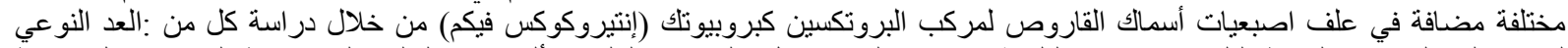

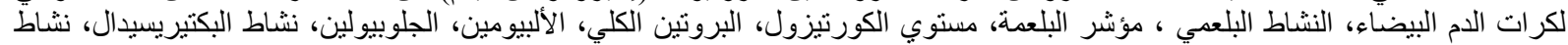

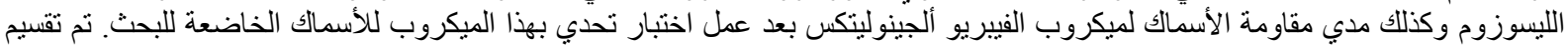

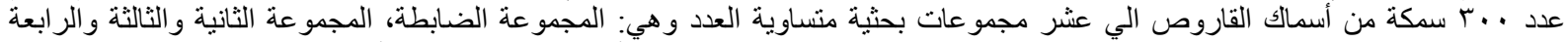

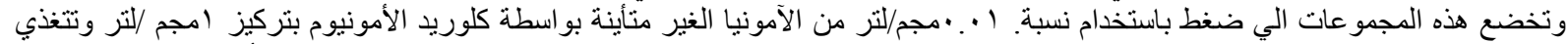

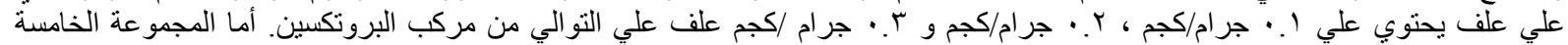

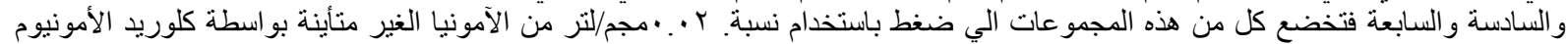

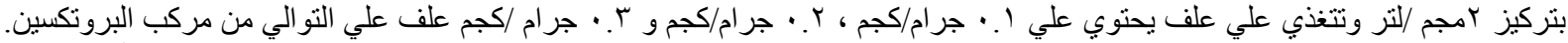

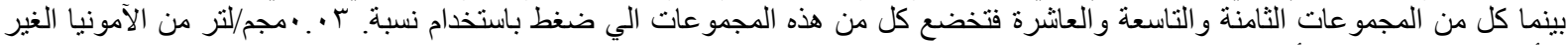

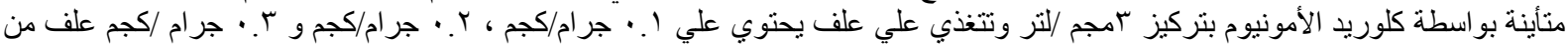

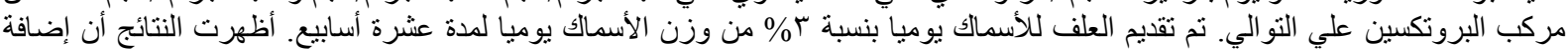

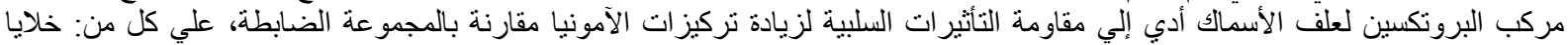

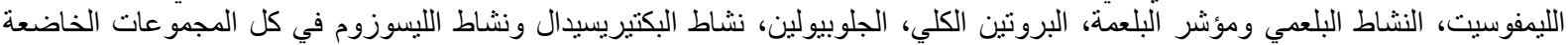

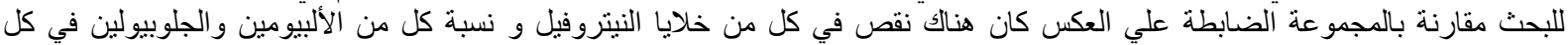

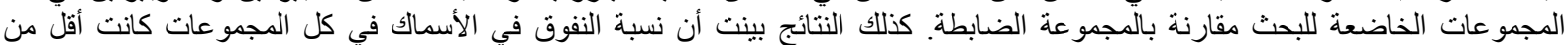

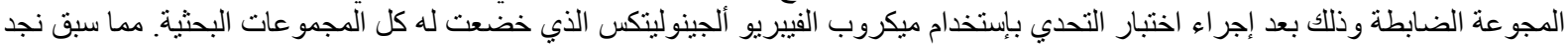

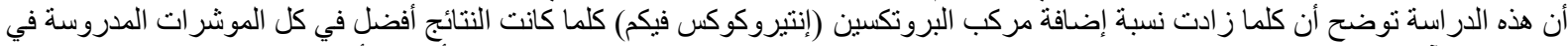

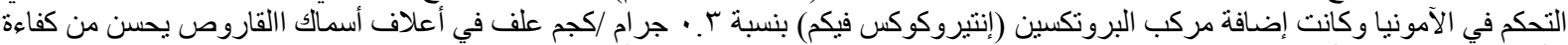

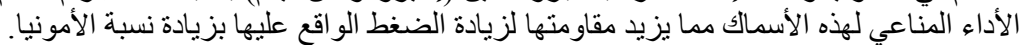

